\title{
LETTER
}

\author{
J. C. Gerster · J. Dudler
}

\section{Cellulitis caused by Capnocytophaga cynodegmi associated with etanercept treatment in a patient with rheumatoid arthritis}

Received: 2 April 2004 / Accepted: 2 April 2004/Published online: 14 July 2004

(C) Clinical Rheumatology 2004

Capnocytophaga are facultative anaerobic gram-negative bacteria, part of the normal flora of the oral cavity of humans and domestic animals such as dogs and cats. There are two main pathogenic species isolated from animal sources, $C$. canimorsus and $C$. cynodegmi [2]. Three species of Capnocytophaga have been isolated from human sources: $C$. ochronacea, $C$. gingivalis and C. sputigena [1].

Bacteria are inoculated by direct dog or cat bite and cause local, or very rarely, disseminated infections. Splenectomy, chronic alcoholism and diabetes mellitus have all been reported to be significant risk factors $[1,2$, $3]$. In recent years, use of tumor necrosis factor (TNF)- $\alpha$ blocking agents to treat rheumatoid arthritis (RA) has increased, but concerns have arisen about opportunistic infections with these therapies [4]. We report the case of a patient treated with etanercept for RA who developed local cellulitis a few days after a bite from her own cat.

\section{Case report}

A 63-year-old RA patient treated successively with gold salts, sulfasalazine, methotrexate and leflunomide over the years was given etanercept $25 \mathrm{mg}$ twice weekly in November 2002. Treatment was concomitant with prednisone $7.5 \mathrm{mg}$ daily, diclofenac $75 \mathrm{mg}$ daily and hydroxychloroquine $400 \mathrm{mg}$ once a day, three medications she had started many years before.

In March 2003, she was bitten by her cat on the left shin. A few days later, she developed a painful swelling of the calf. She was afebrile and had no signs of RA flare. Red pinkish nodules, about $4 \times 5 \mathrm{~cm}$ in size, on the anterior part of the left calf necrosed secondarily after a few days (Fig. 1). There was no purulent

J. C. Gerster $(\bowtie) \cdot$ J. Dudler

Rheumatology Department, CHUV,

1011 Lausanne, Switzerland

E-mail: Jean-Charles.Gerster@chuv.hospvd.ch discharge, no lymphangitis or inguinal lymphadenopathy. A small bite scar, $4 \mathrm{~mm}$ in length, could be seen. Bacteria of the species Capnocytophaga grew in the microbiologic specimens collected by needle aspiration. C. cynodegmi was identified by amplification and sequencing of the $16 \mathrm{~S}$ rRNA. The erythrocyte sedimentation rate (ESR) was $26 \mathrm{~mm} / \mathrm{h}$, leucocyte count $10,500 / \mathrm{mm}^{3}$ with a normal differential and haemoglobin $127 \mathrm{~g} / \mathrm{l}$. Clarithromycin $1 \mathrm{~g}$ daily was given for 10 days and etanercept interrupted. Evolution was favourable; the cutaneous lesions healed progressively without sequelae.

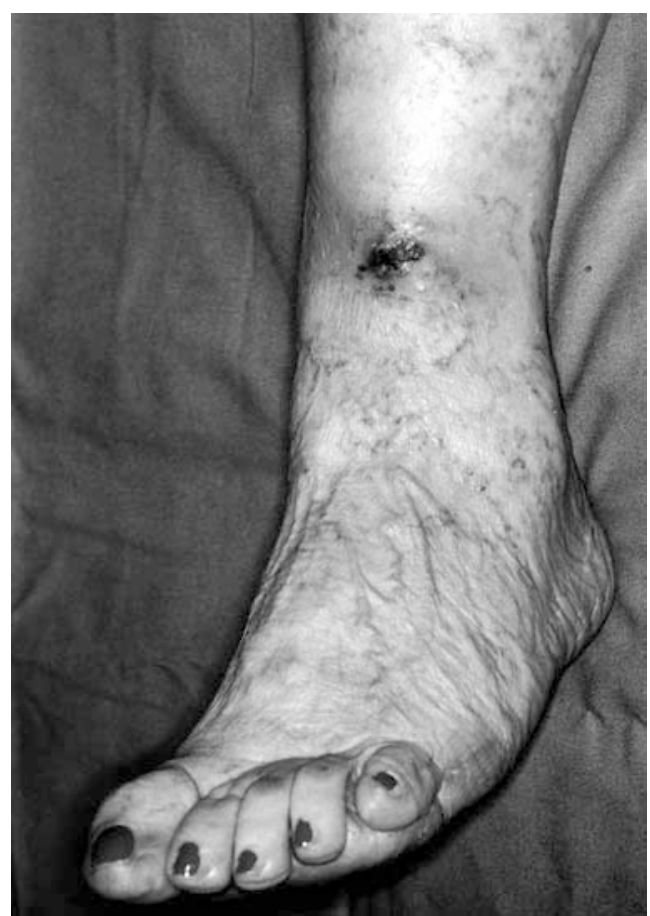

Fig. 1 Local skin necrosis related to $\mathrm{C}$ apnocytophaga cynodegmi local infection 


\section{Discussion}

Capnocytophaga represent an opportunistic germ of low pathogenicity, part of normal oral flora. In some cases, these bacteria can cause a local abscess [5] or even septicaemia with a fatality rate as high as $25 \%$ [6]. Infections with these microorganisms have been previously reported in immunocompromised hosts [2]. In our patient, long-term corticosteroid therapy could by itself be a predisposing factor. However, anti-TNF- $\alpha$ therapy appears to have played a more important role in this infection as our patient had been bitten by her cats on numerous occasions over the years, without previous problem.

In our review of the literature, we did not find reports of Capnocytophaga infection in association with TNF- $\alpha$ blocking agents, a germ which does not seem to cause arthritis, in contrast to Pasteurella multocida also transmitted by scratches or domestic animal bites, which can cause severe arthritis [7].

\section{References}

1. Talan DA, Citron DM, Abrahamian FM, Moran GJ, Goldstein EJC (1999) Bacteriologic analysis of infected dog and cat bites. N Engl J Med 340:85-92

2. Scully RE, Mark EJ, McNeely WF, Ebeling SH, Ellender SM (1999) Case records of the Massachusetts General Hospital, case 17-1999. N Engl J Med 340:1819-1826

3. Sarma PS, Mohanty S (2001) Capnocytophaga cynodegmi cellulitis, bacteremia and pneumonitis in a diabetic man. J Clin Microbiol 39:2028-2029

4. Ellerin T, Rubin RH, Weinblatt ME (2003) Infections and antitumor necrosis factor $\alpha$ therapy. Arthritis Rheum 48:3013-3022

5. Henzen C, Streit E (1993) Zervikalabszess durch Capnocytophaga ochracea. Schweiz Med Wochenschr 123:1165-1168

6. Pers C, Gahrn-Hansen B, Frederiksen W (1996) Capnocytophaga canimorsus septicemia in Denmark, 1982-1995: review of 39 cases. Clin Infect Dis 23:71-75

7. Chevalier X (2003) Attention quand le chat sort ses griffes! A propos d'arthrites septiques. Lett Rhumatol 296: 35-40 